Tropical Journal of Pharmaceutical Research March 2014; 13 (3): 455-457

ISSN: $1596-5996$ (print); 1596-9827 (electronic)

(C) Pharmacotherapy Group, Faculty of Pharmacy, University of Benin, Benin City, 300001 Nigeria.

All rights reserved.

Available online at http://www.tjpr.org

http://dx.doi.org/10.4314/tjpr.v13i3.21

Case Report

\title{
Reported Case of Paracetamol and Non-Steroidal Anti- Inflammatory Drug (NSAID)-Induced Seizures in a Patient with HIV Infection
}

\author{
Oguamanam Okezie Enwere ${ }^{1}$ and Chinedu Valentine Eze ${ }^{2}$ \\ ${ }^{1}$ Department of Medicine, Faculty of Medicine, Imo State University, Orlu Campus, ${ }^{2}$ Department of Internal Medicine, Imo State \\ University Teaching Hospital, Umuna Orlu, Imo State, Nigeria.
}

*For correspondence: Email: okeyzie@yahoo.com; Tel: +2348033260826

Received: 18 April 2013

Revised accepted: 30 January 2014

\begin{abstract}
Commonly available analgesics, such as paracetamol and non-steroidal anti-inflammatory drugs (NSAIDs), are used widely with few or no adverse events by most individuals. However, some adverse events have been observed following the use of these drugs. This paper reports a case of paracetamol and NSAID-induced seizures in a patient with the human immunodeficiency virus infection/acquired immune deficiency syndrome (HIVIAIDS). These seizures occurred at different times, first with paracetamol and then diclofenac (a NSAID). She was concurrently on anti-retroviral drugs and antibiotics. We were unable to readily explain this unusual adverse event as most documented paracetamol-related adverse events are either immunoglobulin $E$ (IgE)-mediated or due to direct paracetamol-induced hepatic necrosis following an overdose. This case is a probable drug-drug interaction not supported by existing literature, and it is possible that the background HIV infection may have a role to play.
\end{abstract}

Keywords: Paracetamol, Diclofenac, Adverse events, Seizures, HIVIAIDS.

Tropical Journal of Pharmaceutical Research is indexed by Science Citation Index (SciSearch), Scopus, International Pharmaceutical Abstract, Chemical Abstracts, Embase, Index Copernicus, EBSCO, African Index Medicus, JournalSeek, Journal Citation Reports/Science Edition, Directory of Open Access Journals (DOAJ), African Journal Online, Bioline International, Open-J-Gate and Pharmacy Abstracts

\section{INTRODUCTION}

Paracetamol and other analgesics such as nonsteroidal anti-inflammatory drugs (NSAIDs) are commonly used medications that are also readily available over-the-counter (OTC). While the medications have analgesic properties, paracetamol unlike NSAIDs lack antiinflammatory properties. Allergic reactions to paracetamol have been widely reported and studied in various parts of the world [1-4]. Some of the reported reactions range from urticaria and angioedema to severe skin eruptions like toxic epidermal necrolysis. Other reported reactions to paracetamol include rhinitis, conjunctivitis, abdominal pain and bronchospasm $[1,5]$. Some of these reactions are thought to be immunoglobulin E (IgE)-mediated [1].

In Nigeria, fixed drug eruption following use of paracetamol and a NSAID (naproxen) have been reported [6] but to the best of our knowledge, no case of seizure has been reported. In this report a case of paracetamol and NSAID-induced seizures in a patient with HIV infection after obtaining informed consent from the patient has been presented.

\section{Case report}

Mrs O. is a 42 year old lady diagnosed in 2010 with HIV infection but she declined taking antiretroviral therapy (ART) until December 2012 
when she reported to the hospital with a febrile illness, cough and weight loss. She was given oral paracetemol $(1000 \mathrm{mg})$ on account of fever. Twenty (20) minutes later, she started sweating profusely and soon developed generalized jerky movements of the body suggestive of a tonicclonic seizure which lasted about $6 \mathrm{~min}$. She subsequently became weak and fell asleep. There was no rash, vomiting or loss of sphincteric control. She had used paracetamol several times in the past prior to being diagnosed with HIV infection without any observed adverse effects. She had had no previous reactions to medications especially ARTs (zidovudine and nevirapine) and co-trimoxazole. She was discharged after a few days when no other suspected adverse reaction was observed. She was not placed on anti-seizure drugs.

In March 2013 she was admitted on account of fever, cough, dyspnoea, weight loss and leg swelling. Clinically she had right pleural effusion. She was prescribed intravenous ceftriaxone and metronidazole as well as given intramuscular paracetamol $600 \mathrm{mg}$ (of a different brand) about two hours prior to administration of the antibiotics, on account of high fever. About 20 min later, she developed similar symptoms to the one stated above, i.e., sweating profusely and development of generalized jerky movement of the body, suggestive of a tonic-clonic seizure which was aborted with injection diazepam. She subsequently fell asleep.

We then decided to control fever with a NSAID (diclofenac). Following administration of oral diclofenac, she developed very similar symptoms to the reaction to paracetamol. She had no history of childhood seizures. There were no signs of meningeal irritation, confusion or focal motor weakness. She was not jaundiced, and liver and kidney functions were normal. Fever was subsequently managed by exposure of her body and tepid sponging. She continued the use of ARTs and antibiotics without developing any reactions.

\section{DISCUSSION}

Reactions to paracetamol and NSAIDs individually or their combined therapy are experienced rarely in clinical practice but awareness of their potential adverse event is becoming common knowledge. In our patient, we did not observe any of such reported reactions as rashes, skin eruption or bronchospam [1-5]. Our patient experienced profuse night sweats followed by generalized jerky movements of the body similar to a tonic-clonic seizure. We were unable to explain this reaction as she did not have other risks for seizures and paracetamol interaction with other medications including the antiretroviral drugs she was taking was unlikely $[7,8]$. She tolerated other medications very well. It is also worthy of note that the first reaction occurred following oral paracetamol while the second reaction occurred following use of a different brand of parenteral paracetamol despite having used paracetamol in the past without a reaction prior to the diagnosis of HIV. Following this reaction we had opted to use a NSAID (diclofenac) to control the fever she was experiencing but a similar reaction was observed.

While many individuals who show allergic reactions to paracetamol may tolerate NSAIDs, it is not unusual for some patients to show allergies to both paracetamol and NSAIDs [1,2,4]. The immediate reaction to paracetamol and diclofenac in our patient may suggest that this may be IgE-mediated but our patient did not exhibit the classic features of paracetamol lgEmediated reaction [1]. It is possible that other mechanisms may be involved in the reaction of this patient. HIV-infected individuals have a higher risk of developing adverse drug events and it is thought that the disease process may play a role in the development of this reaction in our patient.

\section{CONCLUSION}

This case was a challenge that required the dispatch of a report of the case to the National Pharmacovigilance Unit of National Agency for Foods and Drug Administration and Control (NAFDAC) in Nigeria. Observed reactions to paracetamol and NSAIDs are rare but our patient did not experience any of such reported events. The observed reaction may suggest another mechanism, other than IgE-mediated, which may be related to the presence of HIV infection.

\section{CONFLICT OF INTEREST}

The authors declare no conflict of interest in this case

\section{REFERENCES}

1. Rutkowski K, Nasser SM, Ewan PW. Paracetamol hypersensitivity: clinical features, mechanism and role of specific IgE. Int Arch Allergy Immunol. 2012; 159(1): 60-64. doi: 10.1159/000335213.

2. Boussetta K, Ponvert C, Karila C, Bourgeois ML, Blic J, Scheinmann $P$. Hypersensitivity reactions to paracetamol in children: a study of 25 cases. Allergy. 2005 Sep;60(9):1174-1177.

3. de Paramo BJ, Gancedo SQ, Cuevas M, Camo IP, Martin $J A$, Cosmes EL. 
Paracetamol (acetaminophen) hypersensitivity. Ann Allergy Asthma Immunol. 2000; 85 (6): 508-511.

4. Daghfous R, El Aidli S, Jday A, Kastalli S, Klouz A, Srairi S, Lakhal M, Loueslati MH, Belkahia C. Allergic reactions to paracetamol. Therapie. 2005; 60(5): 523-526.

5. Corominas M, Lleonart R, Muñoz E. Bronchospasm Induced Selectively by Paracetamol. J Investig Allergol Clin Immunol 2012; 22(1): 70-71.
6. Nnoruka EN, Ikeh VO, Mbah AU. Fixed drug eruption in Nigeria. Int J Dermatol. 2006; 45(9): 1062-1065.

7. Toes Mi, Jones Al, Prescott L. Drug Interactions with paracetamol. Am J Ther. 2005; 12(1): 56-66

8. Amariles $P$, Alzate NG, Faus MJ. Clinical Relevance of Drug Interactions in HIV-Infected Patients Receiving Antiretroviral Therapy. [cited 2013 Apr 13]. Available from http://www. intechopen.com. 